\title{
A VIVÊNCIA DE MULHERES NO PARTO DOMICILIAR E HOSPITALAR
}

\author{
Women Experience with \\ Home and Hospital Childbirth \\ La Vivencia de Mujeres en el \\ Parto Domiciliar y Hospitalario
}

Cilene Delgado Crizóstomo

Inez Sampaio Nery

Maria Helena Barros Luz

\section{Resumo}

Estudo com abordagem qualitativa, objetivando compreender na vivência das mulheres a experiência do parto normal domiciliar e hospitalar bem como discutir a vivência das mulheres nos dois tipos de partos. Os sujeitos do estudo foram sete mulheres multíparas residentes em Batalha -PI, e o instrumento utilizado foi um roteiro semiestruturado com a técnica da entrevista. Os resultados revelaram que os partos domiciliares vivenciados pelas mulheres aconteceram mais rápido, de forma natural, sem intervenções e assistidos por parteiras ou por suas mães. As posições de preferência durante o parto domiciliar foram na rede e no assento, e os partos hospitalares foram laboriosos, complicados e com intervenções traumáticas. A melhor posição e o melhor local do parto escolhidos pelas entrevistadas foram na rede e o domicílio, respectivamente. Conclui-se que o parto domiciliar foi natural e humanizado, já o parto normal hospitalar foi conduzido pelos profissionais com intervenções sem a participação ativa das parturientes, tornando-o traumático, desumano e de risco.

Palavras-chave: Mulheres. Parto Domiciliar. Parto Humanizado.

\begin{abstract}
Qualitative study that aimed to understand the experience of women in natural childbirth at home and at the hospital, as to argue the experience of the women in the both types of birth. The subjects of the study was seven multiparous women that lives in Batalha - Piauí - Brazil, and the used instruments were a half structurized script in a interview. The results revealed that the births at home experienced by women happened faster, in a natural way, without intervention and assisted by midwives or the mother of these women. The positions preferred during the birth at home was in a net and in a seat, and the births at the hospital was difficult, complicated and with traumatic interventions. The best position and the best location of birth, choused by the interviewed women, were the net and the birth at home, respectively. It was concluded that the birth at home was natural and humanized, but the birth at the hospital was conducted by professionals with interventions without the active participation of the pregnant woman, making it traumatic, inhuman and with risk.
\end{abstract}

\section{Keywords:}

Women. Home Childbirth. Humanizing Delivery.

\section{Resumen}

Estudio con abordaje cualitativo, objetivando entender la experiencia de mujeres en parto natural en el domicilio y en el hospital, en cuanto se discute la experiencia de las mujeres en ambos tipos de parto. Los sujetos del estudio fueron siete mujeres multiparas que viven en Batalha - Piauí - Brasil, y los instrumentos usados fueran un guión semi-estructurado con la técnica de la entrevista. Los resultados revelaron que los partos en el domicilio experimentados por las mujeres sucedieron más rápidamente, de una manera natural, sin intervenciones y asistido por parteras o por sus madres. Las posiciones preferidas durante el parto en el domicilio fueron en la red y en el asiento, y los partos en el hospital fueran laboriosos, complicados y con intervenciones traumáticas. La mejor posición y la mejor localización del parto, escogidos por las entrevistadas, fueron la red y el domicilio, respectivamente. Se ha concluido que el parto en el domicilio es natural y humanizado, pero el parto en el hospital fue conducido por los profesionales con intervenciones sin la participación activa de la mujer embarazada, tornándolo traumático, deshumano y de riesgo.

Palabras clave:

Mujeres. Parto Domiciliario. Parto Humanizado. 


\section{INTRODUÇÃO}

0 parto domiciliar não-intervencionista por longo tempo foi prática comum, considerada normal na sociedade. E só a partir do século XX, a medicina transformou o parto, que é um evento fisiológico, em um evento patológico, que necessita, na maioria das vezes, de tratamento medicamentoso e cirúrgico, predominando a assistência hospitalar ao parto, tornando-o, a partir daí, institucionalizado.

0 ambiente onde é realizado o parto é importante, pois este pode ajudar ou atrapalhar a evolução do trabalho de parto. Aqui no Brasil, além do hospital, existem outros locais pouco difundidos, onde o parto é tratado como um processo fisiológico, sobretudo os que ocorrem nas casas de parto e em domicílio'.

Segundo o Ministério da Saúde, embora tenha havido uma queda na Razão da Mortalidade Materna (RMM) a partir da década de 1980 no Brasil, essa RMM permanece elevada. No ano de 2001, a RMM corrigida foi de 74,5 óbitos maternos por 100.000 nascidos vivos, apesar da subinformaçãa e do sub-registro?.

Até o início do século passado, as parteiras, aparadeiras ou comadres eram mulheres de confiança da gestante e/ou reconhecidas pela comunidade por sua experiência na realização do parto e no acompanhamento durante o trabalho de parto e pós-parto, que ocorriam no domicílio, chamado de "cuidar do resguardo". Essas mulheres eram pobres e geralmente pouco ou nada recebiam por seu trabalho; no entanto, faziam disso um sacerdócio. Por ser uma atividade desvalorizada, o parto era deixado aos cuidados femininos, pois além de serem raros os médicos que existiam, estes eram pouco familiarizados com 0 atendimento ao nascimento ${ }^{3}$.

No Brasil Colônia, as mulheres eram preparadas para parir na posição agachada ou sentada e contavam com o trabalho das parteiras. Os médicos se mostravam insensíveis à dor das parturientes. Por isso, as mulheres preferiam as parteiras por razões psicológicas, humanitárias e devido ao tabu de mostrar a genitália. Estas conheciam a gravidez, o puerpério e manobras que facilitavam o parto por experiência própria, portanto gozavam de enorme prestígio na sociedade ${ }^{3}$.

No final do século XVI, o cirurgião inglês Peter Chamberlain passou a utilizar o fórceps obstétrico com freqüência, fazendo com que o trabalho da parteira, reconhecido pela sociedade, começasse a sofrer declínio. A intervenção masculina passou a substituir o paradigma não-intervencionista das parteiras, e estas passaram a ser rejeitadas ${ }^{3}$.

No início do século XX, os médicos formados nas faculdades brasileiras não possuíam conhecimentos práticos, apenas teóricos, pois nos hospitais não havia gestantes internadas para parir. Após a Segunda Guerra Mundial, o parto no Brasil foi progressivamente institucionalizado, com o crescimento do número de partos hospitalares. Os médicos diminuíram de forma significativa os riscos hospitalares ao incorporarem novos conhecimentos e habilidades nas áreas relativas à cirurgia, assepsia, anestesia, hemo e antibioticoterapia ${ }^{3}$.

As modificações da posição vertical para a deitada, litotômica, semi-sentada, foram sugeridas em Londres e Paris, tendo como causa a comodidade do médico ou do pessoal responsável pelo atendimento ao parto. Ressaltam-se, nesta mudança, o desrespeito aos mecanismos fisiológicos do parto e 0 prejuizo na qualidade do atendimento ao parto normal de baixo risco. Essa alteração passa a ser adotada pela maioria das escolas médicas4.

Vale ressaltar que a Organização Mundial de Saúde propõe mudanças no modelo de atendimento ao parto hospitalar/ medicalizado no Brasil, recomenda a modificação de rotinas hospitalares consideradas desnecessárias, geradoras de risco e excessivamente intervencionistas no que tange ao parto, como episiotomia, amniotomia, enema e tricotomia e, particularmente, parto cesariano. A proposta da OMS não é eliminar tais intervenções, mas reduzi-las apenas às situações de necessidade comprovada, uma vez que se entende que 0 modelo de atenção ao parto e ao nascimento hospitalar estaria abusando de práticas prejudiciais à saúde da mulher e do bebê ${ }^{5}$.

No Brasil, o Ministério da Saúde, visando à humanização da assistência ao parto normal e à redução do índice de morbimortalidade materna e perinatal, em 1998, por meio das portarias Ministeriais $n^{0}$ 2815/98 e $n^{0}$ 2816/98 respectivamente, estabeleceu o pagamento pelo procedimento do parto normal sem distocia à enfermeira obstetra e estabeleceu o pagamento do percentual máximo de cesarianas, e, através da Portaria 163/98, estabeleceu a emissão de laudo de (AlH) de parto normal realizado pela enfermeira ${ }^{6}$.

Ainda em 1999, o Ministério da Saúde publicou outra Portaria de ${ }^{\circ}$ 985/99, criando o centro de parto normal (CPN), no âmbito do SUS, com equipe mínima constituída por uma enfermeira obstetra, uma auxiliar de enfermagem, um auxiliar de serviços gerais e um motorista para 0 atendimento humanizado e de qualidade, exclusivamente ao parto normal sem distocia realizado por enfermeiro obstetra. Essas instituições possuem um ambiente e uma estrutura física semelhante ao domicilio ${ }^{6}$.

Os centros de parto normal e/ou as casas de parto são espaços que estão surgindo e que o(a) enfermeiro(a) obstetra deve ocupar, uma vez que este foi reconhecido pela OMS como o profissional mais adequado e com melhor custo - efetividade de prestador de cuidados de saúde para ser responsável pela assistência à gestação e ao parto normal, incluindo a avaliação de riscos e o reconhecimento de complicações.

Tendo em vista que a enfermagem vem se preocupando e se empenhando cada vez mais na melhoria da assistência, e em especial com a humanização da assistência ao parto normal, pretende-se com este estudo ampliar os conhecimentos sobre a assistência ao parto normal, para contribuir com sua melhoria e humanização.

Para isso, faz-se necessário repensar, refletir e reavaliar qual o melhor local e em que condições as parturientes poderão ter seus filhos, respeitando os seus direitos, levando em consideração os benefícios para os protagonistas de todo 0 processo do nascimento - mãe e filho.

Diante da problemática apresentada, tem-se por objeto de estudo as experiências das mulheres que vivenciaram o parto normal domiciliar e hospitalar. E dentre as questões norteadoras destacaram-se: como foram as experiências das mulheres, com relação aos partos normais que ocorreram no domicílio e no hospital? Qual a melhor experiência, parir no domicílio ou no hospital? Por quê? 
A partir desses questionamentos elaboraram-se os seguintes objetivos: compreender na vivência das mulheres a experiência do parto normal domiciliar e hospitalar e discutir a vivência das mulheres no parto normal no domicílio e no hospital.

\section{METODOLOGIA}

Este estudo é de natureza qualitativa, cujo instrumento utilizado para produção de dados foi um roteiro semiestruturado com dados de identificação e questões abertas. A técnica empregada foi a entrevista previamente agendada nas visitas domiciliares por uma das autoras. As entrevistas foram realizadas no período de março e abril de 2004 no respectivo domićlio de cada participante da pesquisa.

As sete mulheres que aceitaram participar do estudo assinaram um termo de consentimento esclarecido que lhes garantia o sigilo e 0 anonimato exigido pela resolução n 196/ 96 do Conselho Nacional de Saúde. Procederam-se então as entrevistas nas quais os depoimentos foram gravados em fitas magnéticas e transcritos posteriormente.

Ressalta-se que, na enfermagem, a pesquisa qualitativa tem contribuído para a compreensão holística do homem, além de permitir explorar melhor cada situação da assistência. A adoção de modelos para cuidar, embasados nas crenças, nos valores e nas experiências vividas pelo indivíduo, sugere uma fundamentação humanizada do processo saúde-doença, para qual a abordagem compreensiva demonstra ser promissora, pois estuda a vivência, o significado e as experiências vividas sob a perspectiva da clientela assistida ${ }^{7}$.

A pesquisa foi realizada com as mulheres que utilizavam os serviços de planejamento familiar e de controle do câncer de colo de útero do Posto de Saúde na vila Kolping, localizado na periferia da zona urbana do município de Batalha-PI, onde está implantado o Programa de Saúde da Família (PSF). A seleção foi feita com a colaboração dos Agentes Comunitários de Saúde, que fizeram o levantamento, na sua microárea, das mulheres multíparas que já passaram pela experiência do parto normal domiciliar e hospitalar, independente de se encontrar no período gravídico-puerperal, residentes naquela área coberta pela equipe do PSF.

Os dados foram obtidos após sua categorização, através da transcrição das falas gravadas, da leitura e releitura do material, organização e classificação dos relatos com base na fundamentação teórica, respondendo às questões norteadoras e aos objetivos do estudo. As falas dos sujeitos foram analisadas tomando por base conceitos de Bardin (1977), através da análise de conteúdos e com base na literatura da temática em estudo. Para Bardin (1977), a análise de conteúdo se aplica a um conjunto de técnicas de análise de comunicação que contém informações sobre 0 comportamento humano apresentado em forma documental ${ }^{8}$.

\section{RESULTADOS}

Os resultados compreenderam a análise dos relatos das depoentes, com base no referencial teórico que estão distribuídos em quatro categorias.

\section{A Vivência do Parto Domiciliar}

Nesta categoria as sete mulheres relataram como foram suas experiências de vivenciar o parto em casa. Eis alguns depoimentos:

Eu senti as dores e esperava o menino nascer, cortava o umbigo e esperava o resto nascer. No último [referindose ao parto] não tinha ninguém, eu mesma que fiz tudo; depois que nasceu, não demorou 10 minutos e o resto saiu [referindo-se à placenta], aí foram chamar a parteira, e eu não tive nada, e nem a criança. 0 outro [referindo-se ao parto] que eu tive foil ligeiro, aí depois a minha mãe cortou o umbigo. 0 último [referindo-se ao parto] não tinha ninguém, eu mesma que fiz tudo. 0 outro, a minha mãe cortou o cordão (E1)

Tive ajuda só da minha mãe, que pegou [referindo-se ao RN] e cortou o cordão (E2)

A parteira pegou três [referindo-se RN], os outros [referindo-se aos filhos] não deu nem tempo, aí a minha mãe cortava o cordão (E4)

Teve uma que eu tive sozinha, que deu muito trabalho para nascer, aí fiquei esperando a parteira chegar. Quando ela chegou, ela cortou o cordão, ficou esperando a placenta descer, aí passou a noite fazendo remédio azeite de mamona morno e passava no pé da barriga, aí puxou e saiu. Nos outros, quando começava a sentir, aí a parteira ficava na minha casa e dormia. Ela não fazia nada, só o que ela fazia era passar a mão na barriga e nas cadeiras. Graças a Deus eu nunca tive complicação. Quando o RN dá trabalho pra nascer, que bota só a cabeça e o pescoço fora, às vezes ela segura e puxa um pouco, mas é com um jeito, porque tem 0 jeito de puxar, quando a dor vem de novo, enquanto não tem dor não puxa, com a força da dor ela puxa (E5)

Parteira, ela tinha o curso de parteira. Às vezes, quando ela chegava eu já tinha tido, ela só fazia cortar o cordão (E6)

Foi normal, eu sentia dor nas cadeiras, eu sabia que estava com dor de parir quando eu vi o sinal de parir [perdendo líquido], aí ficava andando, caminhando, trabalhando, aí eu mandava chamar a parteira. Ela cuidava de mim, me dava chá de cebola branca, esperava até chegar a hora, ela pegava o menino, às vezes ela fazia toque, ela trazia o material dela todo. Teve um [parto] que eu tive sozinha. Foi rápido, veio com tudo [referindo-se à dequitação], aí chamaram a vizinha $e$ ela cortou o cordão. Eu só ia pra rede ou assento quando não agüentava mais, mas o resto do tempo era caminhando direto até não agüentar mais. Aí o menino nascia, ela cortava o umbigo. Aí banhava, mas agora não banha mais; elas só limpavam ele. Aí ela cuidava de mim, aí quando dava 8 dias, elas iam perguntar como é que eu estava (E7).

Pode-se perceber pelas falas das entrevistadas 1, 5, 7 que os partos ocorridos em casa foram rápidos, de evolução fisiológica, portanto de baixo risco, sem intervenções, onde as 
mesmas tinham toda a liberdade de ficar caminhando e bebendo líquidos, o que tornou a mulher o sujeito ativo do processo parturitivo.

Essas mulheres que pariram no domicílio foram assistidas, na maioria das vezes e predominantemente, por parteiras, embora as entrevistadas 1 e 6 tenham parido sozinhas ou sido assistidas por suas mães, e as entrevistadas 2, 4 e 7 tiveram partos em que receberam assistência somente de suas mães.

Mesmo sem todo o suporte de profissionais qualificados e recursos tecnológicos presentes em uma instituição hospitalar que atende à mulher nesse período, esses depoimentos mostraram partos e pós-partos ausentes de complicações para a mãe e o recém-nascido.

0 parto não é uma doença, é um fenômeno fisiológico, salvo em gestações de risco. Portanto, a grávida não é paciente, pois não está doente, apenas vai parir um bebê, ela é uma parturiente. Acredita-se que cerca de $40 \%$ dos partos possam ocorrer fora dos hospitais, sejam em casas de parto ou nos domicílios, conquanto que atinjam determinadas condições de seguridade. 0 risco existe tanto no domicílio como no hospital. Ainda não se sabe qual dos dois é o de maior risco, se o hospital ou o domicílio, para casos específicos. Acredita-se que ambos tenham suas indicações ${ }^{9}$.

0 parto em casa atende, de maneira particular, às necessidades psicológicas e sociais e também permite a participação e a presença ativa do pai ou companheiro. Possui muitas vantagens, tais como a liberdade de movimentos, segurança, privacidade, condições excepcionais de acolhimento do bebê, necessidades afetivas atendidas e autonomia durante o process $0^{10}$.

0 tipo de formação profissional - de parteira/obstetriz ou de enfermeira obstétrica - tem sido apontado como um fator que influi diretamente na forma de assistência ao parto, sendo considerado menos medicalizado o parto realizado por parteira. Visando a um melhor atendimento às parturientes com a redução do número de intervenções cirúrgicas e medicamentosas desnecessárias, profissionais de diferentes áreas têm defendido a criação de cursos de obstetrícia com exame de seleção e currículo próprios, para formação de parteira/obstetriz (técnico e universitário) ${ }^{11}$.

Apesar da institucionalização do parto, atualmente as parteiras tradicionais continuam prestando assistência à mulher no parto domiciliar no interior do Piauí. Elas possuem uma grande sabedoria e humanidade, o que tem contribuído bastante para essa assistência.

As parteiras em geral passam vários dias na casa da parturiente à espera da hora do parto. Elas rezam, cantam, provêem a casa de tudo que é necessário, auxiliam nos trabalhos domésticos da cozinha, nos cuidados com as crianças, assistem à puérpera, observando sintomas e dando orientações. Vale destacar que "ainda exercem outras funções além da assistência no parto. Seu tempo é livre dedicado ao parto. Possuem uma sabedoria inata, não têm pressa, pois sabem que é prudente observar a natureza e deixá-la agir"10

Em alguns países desenvolvidos, criaram-se centros de parto em hospitais ou fora deles, onde mulheres de baixo risco podem dar à luz numa atmosfera semelhante à domiciliar, com assistência obstétrica primária, em geral aos cuidados de enfermeiras - parteiras. Geralmente esses centros realizam pouca ou menos intervenções, como o monitoramento fetal eletrônico e a correção da dinâmica/aceleração do trabalho de parto, e o uso de analgésicos é mínimo ${ }^{13}$

\section{A Vivência do Parto Hospitalar}

Nesta categoria, as mulheres relataram como foi vivenciado o parto no hospital, conforme os seguintes depoimentos:

No hospital, passei 5 dias tendo as dores, a criança foi empurrada [refere-se à manobra de Kristeler]. Foi mais demorado. E a outra foi puxada também (E2)

O primeiro foi no hospital, eu tive as dores, aí me levaram para o hospital, eu entrei quinta e fui ter sábado. Foi um parto complicado (E4)

Foi porque eu comecei a perder muito líquido, mas não sentia dor de ter [parir]. No outro dia, eu fui para o hospital, aí demorou bastante [parto], aí elas chamaram o doutor e me espremeram [referindo-se a manobra de Kristeler]. Foi o mais demorado de todos [referindo-se aos partos] (E5)

De acordo com os relatos, os partos que aconteceram no hospital foram laboriosos e mais demorados do que o parto em casa. Também foram complicados e com muitas intervenções traumáticas e desnecessárias, como as manobras de Kristeler, ao relatarem que a criança foi "empurrada e puxada".

0 Brasil adotou o modelo americano de assistência ao parto, caracterizado pela medicalização e pelo processo intervencionista, buscando sua institucionalização, adaptandose cada vez mais às novas tecnologias, incorporando-as ao grande número de intervenções e apoiando-se no enfoque de risco. É necessário, portanto, a retomada da prática do parto normal humanizado, com a redescoberta do paradigma da integridade, vendo a mulher de uma maneira holística e o parto como um evento fisiológico ${ }^{13}$.

Os efeitos perversos da tecnologia são numerosos - uma intervenção não justificada geralmente desencadeia muitas outras, cada uma com seus efeitos negativos e posteriormente perigosos à saúde da mãe e do seu filho ${ }^{10}$.

A parturiente deve ser acompanhada por pessoal devidamente capacitado, para que as intervenções ocorram quando necessárias, e não como rotinas, privilegiando o bemestar da parturiente e do concepto, tentando não utilizar métodos invasivos. Esse modelo de assistência é mais característico da assistência pelas enfermeiras, que atuam dentro de uma visão mais humana e holística ${ }^{13}$.

0 parto convencional, em sua maioria, ocorre de uma forma agressiva, em que há muita intervenção externa da equipe que o acompanha. Muitas vezes, a mulher passa por uma série de rotinas que nem sempre é necessária para a aceleração do trabalho de parto, como medicamento, amniotomia, o bebê é afastado da mãe nos primeiros minutos, dentre outros procedimentos ${ }^{14}$.

Atualmente, na rede hospitalar, verifica-se que 0 atendimento à gestante é bastante sofisticado, especialmente nos grandes centros. Esses progressos são importantes, mas a obstetrícia não tem dado ênfase aos aspectos psicológicos e sociais da gravidez e do parto, dando a idéia de estar mais 
preocupada com os aspectos tecnológicos do que com os cuidados às mulheres que vão parir ${ }^{15}$.

Por mais tecnologia que seja usada, nunca será capaz de oferecer uma situação completamente segura para a mãe, feto e recém-nascido. A segurança necessita de estudos mais cuidadosos, não só em relação ao local onde ocorre o parto, mas principalmente no que diz respeito ao tipo de formação das pessoas que 0 assistem ${ }^{15}$.

\section{Posição do Parto Domiciliar e a Preferência das Mulheres}

Nesta categoria, as mulheres relataram as posições de parir no domicílio, que foram no assento e na rede, sendo a primeira a posição mais citada, conforme os depoimentos:

Na rede, deitada, esperando ela nascer, porque não tinha quem me ajudasse (E1)

Foram na rede os dois (E2)

Fico em pé. Fico em pé todo tempo, na hora que eu sinto que vai nascer aí eu entro pra dentro, aí meu marido me segura e a parteira segura o RN (E4)

Era no assento e ficava alguém me segurando (E3, E6)

Na rede e no assento, mas era mais na rede (E7).

A posição de parir no domicílio adotada pelas entrevistadas 1 e 2 foi deitada na rede, por estarem sozinhas. As entrevistadas 3 e 6 pariram no assento; já a entrevistada 4 pariu em pé, com seu marido a segurando, e a E7 pariu tanto na rede como no assento. Observa-se que as mulheres pariram na rede quando não possuíam assistência, e que a posição mais freqüente foi 0 assento.

Estudos realizados no período expulsivo do parto indicam que uma posição verticalizada ou uma inclinação lateral apresentam maiores vantagens do que uma posição dorsal, como:

menor desconforto e dificuldades de puxos; menor dor durante o trabalho de parto; menor traumatismo vaginal ou perineal; menor duração do período expulsivo; melhores resultados neonatais com índices de Apgar < 7. Além disso, a posição vertical (parada ou deambulando), ou em decúbito lateral, está associada a uma maior eficiência e intensidade das contrações ${ }^{16}$.

A posição vertical durante o trabalho de parto está associada ao encurtamento do primeiro período clínico do parto e pode ser indicada como alternativa ao uso da ocitocina para intensificar as contrações uterinas, pois a deambulação é tão efetiva quanto o uso de ocitocina, e a participação ativa da mulher no trabalho de parto também contribuem para redução das taxas de cesarianas ${ }^{17}$.

Quando se indagou às mulheres que tiveram a experiência do par to normal no domicilio e no hospital quais foram o melhor local e a melhor posição de parir, todas elas referiram 0 domicílio como o melhor local, e a posição de parir foi na rede e no assento, e a rede foi a posição preferida, conforme os depoimentos a seguir:

É melhor na rede (E1 e E2 ); No assento (E3);

\section{A posição do hospital é muito mais ruim (E5); \\ É melhor a posição de casa, no assento (E4 e E6)}

Segundo as mulheres, as posições do parto no domicílio, tanto vertical no assento como horizontal na rede, são melhores que a posição litotômica ou ginecológica adotada no hospital.

Cada mulher encontra a sua melhor posição de parir. As posições de cócoras, em pé, sentada, apoiada em alguém de sua confiança ou na rede de dormir, que é um excelente apoio, são as posições que facilitam o parto, além de serem mais cômodas. No primeiro estágio do trabalho de parto, a mulher não deve ser obrigada a permanecer no leito. Deve-se incentivar a mulher a caminhar, a ficar de cócoras e depois em pé, enfim, a se movimentar bastante ou ficar na posição em que ela se sentir melhor. São condições que a gestante pode adotar no trabalho de parto e, em geral, de forma espontânea, existindo uma tendência à alternância de posições ${ }^{16}$.

As entrevistadas 5 e 7 reclamavam da posição litotômica:

A posição do hospital é muito mais ruim (E5);

O pior é ficar "impindurada", porque é quase "impindurada", a posição da gente fica toda esquisita, isso aqui [referindo-se à região perineal e vagina] da gente fica todo dolorido, as cadeiras da gente ficam muito abertas. Em casa você pode pegar no punho da rede e puxar pra baixo. No hospital não tem onde segurar(E7).

A posição horizontal no parto é usada para tornar fácil ao médico fazer seu trabalho. Quando a posição deitada ou reclinada foi proposta, no século XVII, era apenas para o momento do parto, nos séculos subseqüentes, seu uso foi estendido para o trabalho de parto também, principalmente quando a assistência à parturiente passou a ser hospital ${ }^{17}$.

A mesma autora afirma também que a prevalência de episiotomia foi maior em hospitais que adotavam a posição litotômica e menor nos que admitiam as posições alternativas; portanto, existe uma associação significante entre o uso de outras posições que não a litotômica e menores taxas de episiotomia. Realizando a episiotomia na maioria das pacientes, reforça-se nos médicos a noção de que o parto é um procedimento cirúrgico ${ }^{17}$.

\section{A Melhor Experiência Vivenciada}

Ao indagar às mulheres acerca de qual a melhor experiência no parto e quais as razões, com relação ao local de parir, seis delas referiram ser o parto domiciliar o melhor, por diversos motivos. As mulheres assim se expressaram:

Foi tudo a mesma coisa. Tudo que a parteira fez o doutor fez também. Eu acho que em casa eu me senti melhor assim, porque quando eu cheguei do hospital, eu estava toda machucada, dolorida, eu dei até febre. Já em casa os dois que eu tive, eu não tive nada disso, eu me senti melhor. Lá faz muito toque machuca muito, eu fiquei toda dolorida, demorou [referindo-se ao parto]. Em casa ela só faz um toque quando está perto, foi mais rápido (E3)

Eu acho melhor em casa, porque o primeiro eu sofri muito, aí eu fiquei com medo, eu fui judiada no hospital 
(..) elas só faziam aqueles toques, aquelas coisas e eu já estava toda inchada. Eu não gosto de hospital, sinto mais segura em casa (E4);

Eu achei melhor em casa, porque no hospital é ruim da gente andar. E na casa da gente vai por todo lugar, fazia as coisas, varria, pegava água (E5)

Eu achava melhor o parto em casa, porque a gente já ficava logo na casa da gente. Só que no hospital, quando às vezes a gente fica sentindo uma dor, a gente toma injeção, toma um soro. Quando a gente pare sozinha não tem remédio. No hospital se correr um risco, 0 médico salva a gente, e, em casa, não (E6)

Conforme os depoimentos, seis mulheres optaram pelo parto domiciliar por diversas razões, dentre elas: maior rapidez, menos intervenções, como a não-realização do toque vaginal, ter a presença de familiares, ter mais liberdade para movimentar-se e emitir sons durante as dores das contrações uterinas. Enquanto no hospital, elas referiram que o parto era mais demorado, realizavam muitos toques que as deixavam machucadas, não poderiam se movimentar e eram transportadas várias vezes de um local para outro.

Existem outras razões, em ordem de importância, que fazem as mulheres optarem pelo parto no lar, como o controle de sua própria experiência de parir; experiência obtida pela própria família; a não-interferência nos processos naturais do parto; cuidados personalizados à parturiente e o baixo custo do parto ${ }^{6}$.

Estudos realizados em uma casa de parto no Rio de Janeiro evidenciou o grau de satisfação das mulheres com seu atendimento, relatando como fatores: um ambiente acolhedor, a presença contínua de um acompanhante durante 0 trabalho de parto, o estímulo à liberdade e poucas intervenções ${ }^{18}$.

No caso das entrevistadas 2 e 7, houve dúvida e ambigüidade nos depoimentos:

Eu não sei nem dizer. A dor é uma só. Em casa a gente tem medo de morrer. No hospital qualquer problema eles podem socorrer (E2)

Eu acho que tudo é uma coisa só, porque se você está em casa você sofre, e se está no hospital sofre também. Eu não sei nem dizer. Em casa eu acho melhor, porque a gente termina de ganhar o seu bebê, já fica ali quietinha naquela posição na rede ou na cama, ninguém fica preocupando, terminava [o parto] eu ficava tranqüila numa boa. No hospital me tiram do lugar, me carregam de lugar pro outro, é muito ruim, porque a mulher não fica normal, ela fica toda doída, é melhor ficar quietinha, tranqüila (E7)

A partir destes depoimentos, pode-se comprovar a importância das recomendaç̃̃es para a humanização do parto e nascimento, e entre elas está a unificação da sala de pré-parto, parto e puerpério (sala PPP), pois transferir uma parturiente da sala de pré-parto para a sala de parto é muito penoso, além de ser uma conduta que cria tensão entre os profissionais ${ }^{14}$.

0 parto humanizado resgata a naturalidade desse momento para a mulher, para sua família e para a equipe de profissionais envolvida. A idéia do parto humanizado é fazer com que 0 parto, geralmente objeto de medos e tensões, siga a ordem natural das coisas, obedecendo ao ritmo e às necessidades específicas do corpo de cada mulher, com profissionais interferindo o mínimo possível durante o processo parturitivo no momento de a mãe trazer uma criança ao mundo ${ }^{5}$.

Nas instituições hospitalares onde o médico é responsável pelo parto, a enfermeira desenvolve um modelo de assistência em função do trabalho do médico, e não do trabalho de parto. 0 seu trabalho está condicionado ao modo de atuação do médico de plantão. Portanto, como os centros de nascimentos e casas de parto utilizam tecnologia apropriada, e é onde o parto normal fica a cargo de enfermeiras obstétricas, a assistência é menos intervencionista e o parto é mais humanizado ${ }^{6}$.

\section{CONSIDERAÇÕES FINAIS}

Nesta pesquisa observou-se que os partos que ocorriam no domicílio foram rápidos, de forma natural, ou seja, de evolução fisiológica, sem intervenções e principalmente sem complicações para a mãe e o recém-nascido. Já os partos que aconteceram no hospital, foram laboriosos e mais demorados, com muitas intervenções traumáticas e desnecessárias, motivos pelos quais as mulheres optaram pelo parto normal domiciliar como a melhor experiência vivenciada.

Com base neste estudo, pode-se afirmar que o parto domiciliar ocorre de forma natural, humanizada e que as parteiras tradicionais têm muita experiência, contribuindo na assistência ao parto. Os fatores que favoreceram a ocorrência de um parto normal de evolução fisiológica no ambiente domiciliar foram: a posição do parto, que geralmente é verticalizada, a liberdade de movimento, pouca ou nenhuma intervenção, a presença de familiares que fazem diminuir a tensão e ansiedade, dando apoio psicológico.

0 progresso tecnológico e científico da obstetrícia e a institucionalização do parto foram importantes e de grande valia para a assistência à gestante e ao parto de alto risco, embora a mortalidade materna e perinatal permaneça alta, e o parto de evolução fisiológica tornou-se de risco, devido ao excesso de intervenções desnecessárias e de assistência desumanizada.

Portanto, há uma necessidade, por parte da clientela, da implantação de um maior número de casas de partos, que se assemelhem ao domićlio, tendo em vista ser inviável o retorno ao parto domiciliar na sociedade moderna e nas grandes cidades, onde não existem mais parteiras tradicionais ${ }^{13}$.

Assim sendo é imprescindivel que os profissionais de enfermagem reflitam sobre as vantagens e desvantagens de cada tipo de parto, sobre as condições mais humanas e seguras para o nascimento de uma criança, analisando a forma de atendimento que é oferecida à mulher nos serviços de saúde.

Conclui-se que o Ministério da Saúde deve envidar mais esforços no sentido de melhorar cada vez mais a assistência à mulher no processo parturitivo com assistência mais humanizada e menos intervencionista. 


\section{Referências}

1. Prado AA. Resgatando o parto. [online] [citado $29 \mathrm{dez} 2002$ ]. Disponível em: www.amigasdoparto.com.br/

2. Ministério da Saúde(BR). Política Nacional de Atenção à Saúde da Mulher: princípios e diretrizes. Brasília; 2004

3. Brüggemann OM. Resgatando a história obstétrica para vislumbrar a melodia da humanização. In: Oliveira ME, Zampieri MFM, Brüggemann OM, organizadores. A melodia da humanização: reflexões sobre o cuidado no processo do nascimento. Florianópolis(SC): Cidade Futura; 2001. p. 23-30

4. Collaço VS. Parto vertical: vivência do casal na dimensão cultural no processo de parir. Florianópolis (SC): Cidade Futura; 2002. p. 25-28

5. Tornquist CS. Armadilhas da nova era: natureza e maternidade no ideário da humanização do parto. Rev Estud Fem 2002 jul/dez; 10 (2).

6. Caparroz SC. 0 resgate do parto normal: contribuições de uma tecnologia apropriada. Joinville (SC): Univille; 2003.p. 10-50

7. Merighi MAB, Praça NS. Abordagens teóricos-metodológicas qualitativas: a vivência da mulher no período reprodutivo. São Paulo (SP): Guanabara Koogan; 2003. p.1

8. Bardin L. Análise de conteúdo. Lisboa(PO): Ed 70; 1977.

9. Meira AS. Parto domiciliar / clínica / casa de parto: meios alternativos para um parto humanizado. [on-line]. [citado 01 fev 2003]. Disponivel em: www.planetanatural.com.br

10. Largura M. A assistência ao parto no Brasil: uma análise crítica. São Paulo (SP); 1998, p. 1-84

11. Mott ML. Parto. Rev Estud Fem 2002 jul/dez; 10 (2).

12. Organização Mundial de Saúde (OMS). Maternidade segura: assistência ao parto normal - um guia prático. Genebra(SW);1996. p. 6

13. Davim RMB, Menezes RMP. Assistência ao parto normal no domicílio. Rev Latino-Am Enfermagem 2001 nov; 9 (6 ) .
14. Amigas do Parto. Recomendações para humanização do parto e nascimento. In: Manual do Parto Humanizado. Projeto Luz da Jica. [on-line] [citado 29 dez 2002] Disponível em: www.amigasdoparto.com.br

15. Rocha MIM. Opinião de primigesta e de mães presentes em serviços de higiene, pré-natal e serviços de higiene infantil de TeresinaPI. [dissertação de mestrado] São Paulo (SP): Escola Paulista de Medicina; 1982. p. 1-18

16. Ministério da Saúde (BR) Curumim G (ONG). Trabalhando com parteiras tradicionais. Brasília (DF): MS/ Grupo Curumim; 2000.

17. Osava RH. Assistência ao parto no Brasil: a participação dos não médicos. [tese de doutorado]. São Paulo(SP: Faculdade de Saúde Publica /USP; 1997. p. 120-30

18. Progianti JM, Vargens OMC, Porfírio AB, Lorenzoni DP. A preservação perineal como prática de enfermeiras obstétricas. Esc Anna Nery Rev Enferm 2006 ago; 10(2): 266-71

\section{Sobre as Autoras}

\section{Cilene Delgado Crizóstomo}

Especialista em Enfermagem Obstétrica da UFPI; Prof ${ }^{a}$ da Faculdade NOVAFAPI, FACID, em Teresina-PI. E-mail: cilenecrizostomo@bol.com.br

\section{Inez Sampaio Nery}

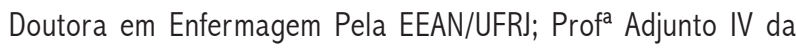
Universidade Federal Piauí. E-mail: nery@webone.br

\section{Maria Helena Barros Luz}

Doutora em enfermagem pela EEAN-UFRJ; Profa Adjunto IV da Universidade Federal Piauí. 